\title{
O TRABALHO ANÁLOGO AO ESCRAVO NA CADEIA PRODUTIVA REGIONAL DO AÇAÍ: UMA ANÁLISE ACERCA DAS RELAÇÕES E DAS CONDIÇÕES DE TRABALHO NA CADEIA DE VALOR
}

\author{
Laís de Castro Soeiro ${ }^{1}$ \\ Suzy Elizabeth Cavalcante Koury ${ }^{2}$
}

\section{RESUMO:}

O presente artigo propõe-se a discutir a existência de trabalho análogo à escravidão na cadeia produtiva regional do açaí, para tanto, utiliza-se a pesquisa bibliográfica, documental e jurisprudencial. Os objetivos são apresentar o conceito de trabalho escravo; compreender como se organizam as relações e as condições de trabalho dos trabalhadores inseridos nessa cadeia de produção; analisar o caso dos trabalhadores resgatados em situação de trabalho análogo ao escravo na extração do açaí, na Ilha do Marajó, no Pará. Por fim, buscar-se-á discutir os avanços e os desafios no combate ao trabalho escravo na cadeia produtiva do açaí, na região Amazônica.

PALAVRAS-CHAVE: Direito do Trabalho; Trabalho Escravo; Cadeias Produtivas; Amazônia; Açaí

\section{ANALOGUE SLAVE WORK IN THE AÇAÍ REGIONAL PRODUCTIVE CHAIN: AN ANALYSIS ABOUT THE RELATIONSHIPS AND WORKING CONDITIONS IN THE VALUE CHAIN}

\begin{abstract}
This article proposes to discuss the existence of work analogous to slavery in the regional açaí productive chain. For this purpose, bibliographic, documentary and jurisprudential research is used. The objectives are to present the concept of slave labor; understand how the relations and working conditions of workers in this production chain are organized; to analyze the case of workers rescued in situations of work analogous to slavery in the extraction of açaí, on Marajó Island, in Pará. Finally, we will seek to discuss the advances and challenges in combating slave labor in the açaí production chain, in the Amazon region.
\end{abstract}

KEYWORDS: Labor Law; Slavery; Productive Chains; Amazon; Açaí

\section{INTRODUÇÃO}

A abolição não foi suficiente para sanar os problemas causados pela escravidão, nem tampouco garantiu um mercado de trabalho livre porque não houve preocupação com o

\footnotetext{
${ }^{1}$ Mestranda em Direito, Políticas Públicas e Desenvolvimento Regional, pelo Programa de Pós-Graduação do Centro Universitário do Estado do Pará (CESUPA). Integrante do Grupo de Pesquisa em Trabalho Decente e do Grupo de Pesquisa Novas Formas de Trabalho, Velhas Práticas Escravistas. Advogada.

${ }^{2}$ Desembargadora do TRT da $8^{a}$ Região. Conselheira do CSJT. Doutora em Direito pela UFMG. Professora do Curso de Direito e do Programa de Pós-Graduação stricto sensu Mestrado em Direito, Políticas Públicas e Desenvolvimento Regional do Centro Universitário do Pará - CESUPA.
} 
desenvolvimento de políticas públicas de inserção dos recém libertos no mercado de trabalho, os quais foram relegados à situação de extrema pobreza e abandono social.

Em pleno século XXI, ainda podemos encontrar trabalhadores submetidos a condições análogas à de escravo, que violam a dignidade humana e são uma grave afronta aos direitos humanos, no plano internacional, e aos direitos fundamentais, no plano interno.

Antes, o artigo 149 do código penal dizia somente "reduzir alguém a condição análoga de escravo", redação genérica e sujeita e interpretações distintas. Entretanto, com a modificação realizada em 2003, a nova redação passou a ser a seguinte:

Art. 149: Reduzir alguém à condição análoga a de escravo, quer submetendo-o a trabalhos forçados ou a jornada exaustiva, quer sujeitando-o a condições degradantes de trabalho, quer restringindo, por qualquer meio, sua locomoção em razão de dívida contraída com o empregador ou preposto. (Grifo nosso)

Existe uma forte discussão doutrinária e jurisprudencial a respeito do bem jurídico tutelado pelo artigo 149 do código penal, para alguns, a liberdade individual, para outros, o artigo vai além e busca tutelar a dignidade humana.

É certo que o trabalho análogo ao escravo não afeta somente a liberdade do indivíduo, mas o expõe a condições de trabalho degradantes, que ferem a sua dignidade, atributo inerente à pessoa, ou seja, todo ser humano é dotado desse preceito, e tal constitui o princípio máximo do estado democrático de direito.

$\mathrm{Na}$ Amazônia, o trabalho escravo, da forma como comumente a vemos, está intimamente ligada ao processo de colonização da região durante os anos 60 e 70, no auge do governo militar no Brasil, bem como, antes, com a extração do látex e o nascimento do ciclo da borracha que se cria uma prática de superexploração de trabalhadores, em condições análogas à escravidão, na região Amazônica, em meados do século XIX.

Movidos por uma política econômica e ideológica de expansão e proteção das fronteiras brasileiras, o governo incentivou o processo migratório de diversas populações desafortunadas, oriundas da região nordeste do país, para nossa região.

Percebe-se que é na forma de ocupação e exploração da Amazônia que se encontram as principais causas do trabalho análogo ao escravo. 
O açaí é um fruto que tem desempenhado um papel importante na economia da Região Amazônica, movimentando cerca de 1,5 bilhões de reais só no estado do Pará, principal produtor e exportador. O estado é responsável por 95\% da produção do fruto (IBGE, 2019).

No entanto, as discussões acerca da cadeia produtiva do açaí e de como ela se organiza ainda são recentes e incipientes, principalmente no tocante à precariedade da atividade e às condições de trabalho inseridos nesse espaço. A questão do trabalho precário na cadeia de valor do açaí nunca foi tratada com a amplitude necessária.

Os trabalhadores responsáveis pela extração do fruto utilizam utensílios rudimentares, fabricados por eles próprios, para realizar a extração, de modo rústico, manual, e precário. A atividade tipicamente relacionada ao sustento da família, em um regime de agricultura e extrativismo familiar, tornou-se um produto de crescente demanda, voltada ao mercado nacional e global (FUNDACENTRO, 2016).

Assim, o que antes era considerado parte do aprendizado no processo de reprodução da agricultura e extrativismo tradicionais, passou ser enquadrado em um ambiente de trabalho de uma cadeia global (FUNDACENTRO, 2016).

O que mais chama a atenção é o grau de precariedade da atividade. Medidas simples podem diminuir significativamente os riscos, as quais, certamente, não foram adotadas. Isso porque os agentes que compõem a cadeia de valor - desde os atravessadores, industriais, batedores de açaí (processadores locais), atacadistas e varejistas - não se interessam pela condição do trabalho do extrativista, da mesma forma o consumidor final desconhece a precariedade do trabalho, deixando de pressionar os elos mais fortes da cadeia de valor para exigir que as relações de trabalho não sejam ainda mais precárias. (FUNDACENTRO, 2016).

O trabalho análogo ao escravo é um problema que afeta, indistintamente, todos os países do globo, sendo objeto de discussão e de preocupação, no Brasil e nas demais nações. No entanto, o presente estudo será direcionado à Região Amazônica e às relações de trabalho nela desenvolvidas, em especial, na cadeia produtiva regional do açaí.

Diante desse cenário, o objetivo do presente estudo é definir quais os avanços e quais os desafios no combate ao trabalho análogo ao escravo na cadeia produtiva do açaí, na Região Amazônica. 
Para isso, utilizar-se-á método dedutivo, baseado em pesquisa bibliográfica, documental e jurisprudencial, para discutir as relações de trabalho existentes na atividade extrativista do açaí e de que forma elas se encaixam no conceito de trabalho análogo ao escravo.

O texto será dividido em três partes. Na primeira, discutiremos o conceito de trabalho análogo à escravidão, as divergências doutrinárias e jurisprudenciais sobre o tema. Após, falaremos sobre as relações e as condições de trabalho existentes na cadeia produtiva do açaí, na Região Amazônica. Segue-se a análise do caso dos trabalhadores resgatados no interior de uma fazenda, no Pará. Por fim, pretende-se discutir quais os avanços e quais os desafios no combate a essa prática na região.

\section{O TRABALHO ANÁLOGO À CONDIÇÃO DE ESCRAVO}

O combate ao trabalho escravo vem-se desenvolvendo de forma sistematizada no Brasil. Apesar dos avanços, todos os anos nos defrontamos com novas ocorrências, em um círculo vicioso que dá continuidade a um dos casos mais graves de exploração da mão de obra do trabalhador e de violação da dignidade humana.

Em 2002, houve a constituição da CONAETE (Coordenadoria Nacional de Erradicação e Combate ao Trabalho Escravo) voltada ao combate do trabalho escravo no âmbito do Ministério Público do Trabalho (MPT).

No entanto, ainda há uma forte discussão doutrinária e jurisprudencial a respeito da caracterização do trabalho escravo no Brasil. Em decorrência disso, em 2003, a Lei 10.803/2003 alterou a redação do artigo 149 do Código Penal, que, até então dizia somente "Reduzir alguém à condição análoga de escravo", sem dúvidas a redação genérica era sujeita a interpretações distintas. A nova redação passou a ser a seguinte:

Art. 149: Reduzir alguém à condição análoga a de escravo, quer submetendo-o a trabalhos forçados ou a jornada exaustiva, quer sujeitando-o a condições degradantes de trabalho, quer restringindo, por qualquer meio, sua locomoção em razão de dívida contraída com o empregador ou preposto. (Grifo nosso)

Pena - reclusão, de dois a oito anos, e multa, além da pena correspondente à violência.

$\S 1^{\circ}$ Nas mesmas penas incorre quem: I - cerceia o uso de qualquer meio de transporte por parte do trabalhador, com $\quad 0$ fim de retê- 
lo no local de trabalho; II - mantém vigilância ostensiva no local de trabalho ou se apodera de documentos ou objetos pessoais do trabalhador, com o fim de retê-lo no local de trabalho.

$\S 2^{\circ}$ A pena é aumentada de metade, se o crime é cometido: I - contra criança ou adolescente; II - por motivo de preconceito de raça, cor, etnia, religião ou origem.

A redação modificou o tipo penal, extremamente sintético e mal compreendido, baseado exclusivamente na restrição à liberdade, transformando-o em um tipo analítico, em que há então a constatação da existência de dois bens jurídicos tutelados pelo artigo, a liberdade e a dignidade da pessoa humana.

A discussão acerca dos bens jurídicos tutelados pelo artigo 149 do CP não comporta mais a ideia de que somente a proteção da liberdade individual seria o bem jurídico a ser tutelado pelo referido artigo, mas, principalmente, a dignidade da pessoa humana.

Outra inovação trazida pela alteração legislativa delimita quais as principais condutas que caracterizam o trabalho escravo, são elas: trabalho forçado; jornada exaustiva; condições degradantes de trabalho e a restrição de qualquer meio de locomoção em razão de dívida.

A nova redação atende ao compromisso internacional assumido em junho de 1965 , pelo estado brasileiro, de combater o trabalho forçado, ao ratificar a Convenção de $\mathrm{n}^{\circ} 105$ (Abolição do Trabalho Forçado) da Organização Internacional do Trabalho (OIT, 1957).

A convenção dispõe em seu artigo $1^{\circ}$ que:

Todo o Membro da Organização Internacional do Trabalho que ratifique a presente convenção compromete-se a suprimir o trabalho forçado ou obrigatório e a não o utilizar sob qualquer forma; Não recorrendo, de forma alguma, a qualquer medida de coerção ou de educação política, quer como sanção a pessoas que tenham ou exprimam certas opiniões políticas ou manifestem a sua oposição ideológica à ordem política, social ou econômica estabelecida; A nenhum método de mobilização e de utilização da mão-deobra com fins de desenvolvimento econômico, ou como medida de disciplina do trabalho; Não recorrendo a nenhuma forma de punição, por ter participado em greves, e, por fim, jamais recorrer ao trabalho forçado ou obrigatório como medida de discriminação racial, social, nacional ou religiosa. (OIT, 1957)

Pode-se entender o trabalho em condições análogas à escravidão como o exercício do trabalho humano em que há restrição, em qualquer forma, à liberdade do trabalhador ou ainda, quando não são respeitados os mínimos direitos para o resguardo da dignidade do trabalhador. (BRITO FILHO, 2005, p. 204) 
Percebe-se que a restrição da liberdade do indivíduo é uma condição, não a única, para a caracterização do trabalho em condições análogas à escravidão. A vítima é privada da liberdade de escolha e da liberdade de execução do trabalho, a uma relação de dominação e sujeição, contra a qual o trabalhador não tem a força necessária para se libertar. O agente que participa dessa relação, enquanto infrator pode ou não agir com violência ou grave ameaça, no entanto, o agente pode aproveitar-se de circunstâncias que a impossibilitem de exercer a opção de não se submeter ao trabalho. (MIRABETE, 2005, p. 184)

Assim, o trabalho análogo ao de escravo ocorre nas situações descritas, quando há um aproveitamento da situação de vulnerabilidade em que o trabalhador está inserido.

Em 2016, houve um significativo avanço legislativo com a alteração do Art. 149-A do Código Penal pela Lei ${ }^{\circ} 13.344$, com isso o artigo passou a ter a seguinte redação:

Art. 149-A. (Caput). Agenciar, aliciar, recrutar, transportar, transferir, comprar, alojar ou acolher pessoa, mediante grave ameaça, violência, coação, fraude ou abuso, com a finalidade de: (Incluído pela Lei $\mathrm{n}^{\circ}$ 13.344, de 2016) (Grifo nosso)

I - remover-lhe órgãos, tecidos ou partes do corpo; (Incluído pela Lei $\mathrm{n}^{\circ}$ 13.344, de 2016)

II - submetê-la a trabalho em condições análogas à de escravo; (Incluído pela Lei no 13.344, de 2016) (Grifo nosso)

III - submetê-la a qualquer tipo de servidão; (Incluído pela Lei n ${ }^{\circ}$ 13.344, de 2016)

IV - adoção ilegal; ou (Incluído pela Lei no 13.344, de 2016)

V - exploração sexual. (Incluído pela Lei nº 13.344, de 2016)

O acréscimo desse artigo contemplou vários núcleos verbais e constituiu um importante avanço normativo no combate (prevenção e repressão) ao trabalho escravo no Brasil.

Isso porque a alteração feita não deixa dúvidas de que não há o crime de redução à condição análoga à de escravo somente quando a liberdade da pessoa é, diretamente, estritamente, suprimida. Não é só ela, todavia, que está em discussão (GRECO, 2008).

A conduta descrita no tipo penal "fere, acima de tudo, o princípio da dignidade humana, despojando-o de todos os seus valores ético-sociais, transformando-o em res, no sentido concebido pelos romanos" (BITENCOURT, 2009).

O trabalho escravo não afeta somente a liberdade do indivíduo, mas o expõe a condições de trabalho que ferem a sua dignidade, o atributo mais valioso do ser humano. A dignidade humana deve ser pensada a partir do conceito elaborado por Immanuel Kant, em sua obra a "Fundamentação da Metafísica dos Costumes", na qual defendia que "As pessoas 
deveriam ser tratadas como um fim em si mesmo, e não como um meio (objetos)" (KANT, 2004, p. 58).

Segundo Kant, há dois parâmetros para a definição da dignidade humana, o preço e a razão, vez que tudo tem ou um preço ou uma dignidade. Se uma coisa tem preço, pode-se substituí-la por qualquer outra coisa equivalente. No entanto, quando uma coisa está acima de todo o preço, e, portanto não permite a troca por equivalência, então ela tem dignidade (KANT, 2003. p. 77).

A Declaração Universal dos Direitos do Homem (DUDH, 1948), fundamentada e nos ensinamentos de Kant acerca da dignidade humana, traz em seu Art. 23, o seguinte:

1. Todo ser humano tem direito ao trabalho, à livre escolha de emprego, a condições justas e favoráveis de trabalho e à proteção contra o desemprego.

2. Todo ser humano, sem qualquer distinção, tem direito a igual remuneração por igual trabalho.

3. Todo ser humano que trabalhe tem direito a uma remuneração justa e satisfatória, que lhe assegure, assim como à sua família, uma existência compatível com a dignidade humana, e a que se acrescentarão, se necessário, outros meios de proteção social. (Grifo Nosso)

4. Todo ser humano tem direito a organizar sindicatos e neles ingressar para proteção de seus interesses.

É possível extrair, em síntese, que os fundamentos trazidos na declaração, quais sejam, a liberdade sindical, a liberdade e a igualdade no trabalho e a proibição ao trabalho infantil, não seriam suficientes para proporcionar uma efetiva proteção dos direitos humanos, o que fundamenta a concepção apresentada por Brito Filho, que amplia ainda o rol de direitos básicos e se propõe a debater o trabalho decente. (BRITO FILHO, 2018, p. 57).

Assevera o autor que não há trabalho decente sem condições adequadas à preservação da vida e da saúde do trabalhador, assim como não há trabalho decente sem justas condições para o trabalho, principalmente no que tange às horas de trabalho e aos períodos de repouso. Não há trabalho decente sem justa remuneração pelo esforço despendido, bem como não há trabalho decente se o Estado não toma as medidas necessárias para a criação e manutenção dos postos de trabalho. Não há, por fim, trabalho decente se o trabalhador não está protegido dos riscos sociais, parte deles originada do próprio trabalho humano. (BRITO FILHO, 2018, p. 57).

A discussão acerca do trabalho escravo é extremamente pertinente no atual momento socioeconômico e político do Brasil. Isso porque convivemos diariamente com diversas 
violações a direitos fundamentais básicos, voltando-se esta análise a tratar dos direitos do trabalhador.

A escravidão está muito mais viva do que muitos pensam, não da forma como estudamos nos livros de história, não legalizada, mas ainda fortemente presente nas relações de trabalho contemporâneas, constantemente precarizadas.

Vivemos em um país em que o trabalhador é constantemente tratado como "objeto", um ser sem dignidade, em que seus direitos são ignorados e retirados de forma brutal e totalmente ilegítima, sendo impossível deixar de citar o total descaso do governo atual com a saúde e com a qualidade de vida dos trabalhadores.

O combate ao trabalho escravo é uma luta antiga, constante e necessária. Muitas conquistas foram alcançadas e o avanço é inegável, infelizmente, esse cenário não apresenta melhoras, e, sem dúvidas, a Região Amazônica é a região de maior abrangência geográfica e uma das mais deficitárias dentro do contexto nacional, isso porque, historicamente, as relações de trabalho desenvolveram-se a partir de constantes violações a direitos fundamentais básicos.

\section{O TRABALHO NA CADEIA PRODUTIVA DO AÇAí}

Devido ao seu desempenho como produto de exportação, o açaí é um dos mais importantes produtos do extrativismo nacional e um dos principais responsáveis por dar visibilidade à biodiversidade da Floresta Amazônica.

A exportação para outras regiões do país concentra-se em especial na região sudeste (São Paulo e Rio de Janeiro), e para outros países, com destaque aos Estados Unidos (EUA), o açaí é atualmente um dos produtos economicamente mais promissores da biodiversidade amazônica.

Além do mercado consumidor externo, o consumo interno do fruto é muito elevado, visto que faz parte da cultura alimentícia do povo paraense. Assim, o Pará tornou-se referência para a economia do açaí por concentrar uma alta produção e um alto consumo (MENDES, 2019).

Em meados da década de 2010, o açaí tornou-se um produto globalmente demandado e conhecido, com aumento considerável da sua exportação para outros estados e países, em virtude da maior demanda no mercado interno e no internacional, o que teve por consequência a necessidade de aumento da produção. 
A relação entre aqueles que exploram essa atividade e aqueles que a realizam diretamente deve ser estudada, como destaca o Instituto Peabiru (2016): "as cadeias de valor tradicionais, relacionadas ao extrativismo e à agricultura familiar, apresentam desafios como a informalidade nas relações de trabalho e a alta insegurança para a saúde no manejo de recursos naturais." (grifo nosso)

Isto ocorre especialmente em cadeias de valor que crescem rapidamente, como é o caso do açaí, que emprega centenas de milhares de pessoas. Infelizmente, os números são frágeis, porque não há dedicação do IBGE para tratá-los corretamente [...] (PEABIRU, 2016)

O extrativismo do açaí de várzea é uma tarefa árdua e arriscada que requer habilidade e extremo vigor físico (CAVALCANTE, 1998), geralmente reservada aos homens na faixa etária entre 12 e 25 anos e peso inferior aos $60 \mathrm{~kg}$.

[...] O processo de escalada é um processo rápido, extremamente perigoso, que consiste em prender os pés com uma argola de fibra (peconha), contrapor os pés ao estipe e envolver a palmeira com as mãos, em seguida, realizar a subida com movimentos de flexão e extensão das costas e das pernas até alcançar o cacho, cortá-lo e trazê-lo até o solo [...] (CANTO, 2001, p.54).

A peconha é uma espécie de anel que é feito com fibras do próprio açaizeiro, em que apoiam os pés que vão de encontro ao caule para subirem com a força de suas pernas e braços, por isso, são denominados “peconheiros” (FERREIRA, KOURY, 2018).

O caule ou estipe é composto de material plástico, como fibras, proteínas e polissacarídeos, têm baixa durabilidade em ambientes externos e a madeira é pesada, mole e racha com facilidade, características que oferecem condições para que o trabalhador escale a palmeira para apanhar os frutos. Assim, o trabalhador utiliza-se da grande flexibilidade do tronco e a emprega para atingir outros estipes, aumentando a produtividade (CANTO, 2001).

As condições de trabalho são precárias e rudimentares, e os trabalhadores realizam suas atividades de forma tradicional, sem o uso dos equipamentos de proteção individual (EPIs) adequados e necessários nesse tipo de atividade, o que pode ocasionar prejuízos à saúde deles. ${ }^{3}$

Segundo dados da Organização Internacional do Trabalho (OIT), cerca de 313 milhões de trabalhadores e trabalhadoras sofrem lesões profissionais não fatais todos os anos,

\footnotetext{
3 Acerca do tema, dispõe o extinto Ministério do Trabalho e Emprego (MTE), na Norma Regulamentadora $n^{\circ} 6$ (NR 6), da Portaria 3.214, considera-se Equipamento de Proteção Individual (EPI) "todo dispositivo ou produto, de uso individual utilizado pelo trabalhador, destinado à proteção de riscos suscetíveis de ameaçar a segurança e a saúde no trabalho" (MTE, 2001).
} 
ou seja, 860.000 pessoas feridas no trabalho todos os dias. Os dados da organização apontam que o Brasil é o quarto país do mundo com maior número de acidentes de trabalho (OIT, 2014).

Estudos recentes, realizados pela Fundação Jorge Duprat Figueiredo de Segurança e Medicina do Trabalho (FUNDACENTRO) em parceria com o Instituto Peabiru, resultado da ação regional do Programa Trabalho Seguro no Tribunal Regional do Trabalho da $8^{\text {a }}$ Região, constataram que as condições de trabalho na atividade extrativista da cadeia de valor do açaí nunca haviam sido tratadas com a amplitude e profundidade até então (FUNDACENTRO, 2016).

Além disso, concluíram que a atividade extrativista da cadeia de valor do açaí é uma das mais perigosas do Brasil, e apresenta alto risco ao trabalhador que a realiza (FUNDACENTRO, 2016).

Durante entrevistas realizadas pela Fundação Jorge Duprat e Figueiredo FUNDACENTRO e pelo Instituto Peabiru (2016), no período de março/2015 a abril/2016, o que chamou a atenção dos pesquisadores, primeiramente, foi o grau de precariedade da atividade realizada pelos trabalhadores e os inúmeros acidentes relatados.

Há sofrimento do trabalhador com o esfolamento nos pés, nas mãos e nas pernas, em razão das inúmeras vezes ao dia em que realiza a extração do fruto, somado a incidentes comuns, como a perda do equilíbrio e o rompimento da peconha; além disso, os trabalhadores relatam dores no peito, nos pés e nas costas.

Outros tipos de ferimentos extremamente comuns são: ferimentos com facas ou facões, utilizados para efetuar o corte dos cachos do açaí, que são colocados, muitas vezes nos bolsos do trabalhador ou até mesmo na boca, na subida e na descida da palmeira.

Devido à altura das palmeiras, que podem medir, aproximadamente, de quinze a vinte e cinco metros, as possíveis quedas podem acarretar ferimentos ainda mais graves, deixando o trabalhador impossibilitado de realizar sua atividade por determinado período.

No diagnóstico realizado pelo Peabiru (2016, pp. 7- 8), foram identificadas, dentre outras, as seguintes situações de risco relacionadas à atividade extrativa do açaí: a caminhada na várzea, o que sujeita os Peconheiros a picadas de animais como cobras, escorpiões e poraquês, e a acidentes envolvendo os pés em virtude de os terrenos serem alagadiços; a passagem por estivas (pinguelas) e outras pontes improvisadas, que são escorregadias, trazendo risco de tombos e baques, dentre outros; a exposição ao sol durante o deslocamento 
em barcos e a pé; o desgaste físico com a subida no açaizeiro e os riscos de cortes, quedas e de empalamento nos antigos troncos de açaizeiros quando da descida; a troca de árvores sem descer, pulando de uma a outra, com imensos riscos de queda e de ferimento com o próprio facão desembainhado que levam nas mãos ou na bermuda (FUNDACENTRO, 2016).

Diante desse cenário, com a ausência de equipamentos de proteção individual adequados, os esforços físicos excessivos e as jornadas exaustivas de trabalho, a atividade, historicamente pautada no modelo extrativista, continua se beneficiando da exploração da mão de obra humana, mantendo e/ou aumentando a desigualdade socioeconômica da região e a invisibilidade da segurança do trabalho perante o consumidor final.

\section{OS TRABALHADORES RESGATADOS NA ILHA DO MARAJÓ (PARÁ)}

Em novembro de 2018, o Grupo Especial de Fiscalização Móvel (GEFM), vinculado ao extinto Ministério do Trabalho, resgatou dezoito trabalhadores, dentre eles dois menores de idade em situação de trabalho análogo ao de escravo na atividade de extrativismo de açaí em várzea, na Ilha do Marajó, no Pará.

Foi o primeiro caso noticiado de trabalhadores resgatados em condições degradantes de trabalho no extrativismo do açaí.

Segundo informações da Auditora fiscal do Trabalho, Andreia Donin, que coordenava a ação, os trabalhadores "Habitavam barracos rústicos de madeira, com coberturas feitas de palhas da folhagem do açaí, telhas de fibrocimento e lonas plásticas, sem fechamento nas laterais, com piso de ripas de madeira ou troncos.” (MTE, 2018). Afirma, ainda, que no local não havia banheiros ou chuveiros e a água consumida era retirada de um rio, sem qualquer tratamento. (MTE, 2018)

A fiscalização também constatou que a atividade é perigosa e submete o trabalhador, o elo mais frágil da cadeia de valor do açaí, a riscos inquestionáveis, que são desconsiderados e permanecem sem interferência gerencial do empregador, que explora economicamente a atividade e assume os riscos do empreendimento (MPT, 2018).

Essa condição degradante de trabalho é uma grave violação aos direitos fundamentais e à ordem jurídica, humana e social, pois viola a dignidade humana do trabalhador desvaloriza a precariza a atividade, instituindo a pobreza, a marginalização, 
ampliando as desigualdades sociais, promovendo diversas formas de discriminação, reduzindo a dignidade da pessoa humana e frustra a justiça social, no âmbito laboral (SAGAZ, 2017).

Os trabalhadores resgatados, de um modo geral, são, em sua maioria, homens, entre 12 e 25 anos e peso inferior aos $60 \mathrm{~kg}$, que possuam conhecimentos especializados no manejo para a extração adequada do fruto, além, é claro, do vigor físico, já tratada anteriormente. (CANTO, 2001).

Os trabalhadores são cobrados pela alimentação e pelos objetos de trabalho, criando uma espécie de servidão por dívida, um dos modos de execução definidos no artigo 149 do Código Penal.

Além disso, os alojamentos precários, a péssima alimentação e a ausência de saneamento básico e água potável, descritas pelos auditores do trabalho, configuram claramente a submissão desses trabalhadores a condições degradantes de trabalho.

Os trabalhadores resgatados receberam os pagamentos relativos às verbas rescisórias do empregador, no valor total de $\mathrm{R} \$ 72.101,66$, além dos valores relativos à indenização por danos morais individuais, no valor total de $\mathrm{R} \$ 230.044,74$, segundo informações contidas no auto de infração; além disso, a auditoria-fiscal do Trabalho lavrou 26 autos de infração pelas irregularidades constatadas (MTE, 2018).

Ainda em 2018, as ações de fiscalização do Grupo Especial de Fiscalização Móvel (GEFM), em cooperação com o Ministério do Trabalho, possibilitaram que 1.311 trabalhadores fossem encontrados, em condições análogas à de escravo, tendo 685 deles sido resgatados. (MTE, 2018).

Desde a criação do Grupo Especial de Fiscalização Móvel (GEFM), em 1995, ligado ao Grupo Executivo de Repressão ao Trabalho Forçado (GETRAF) e à Secretaria de Inspeção do Trabalho (SIT), criado pelo (extinto) Ministério do Trabalho, estima-se que mais de 54 mil pessoas foram resgatadas de condições análogas à escravidão.

Nesses 25 anos de atuação, as equipes do Grupo Móvel, segundo dados do sindicato nacional dos Auditores Fiscais do Trabalho (SINAIT), fiscalizaram mais de 5 mil empresas, fazendas e estabelecimentos. Cerca de 47 mil trabalhadores obtiveram a formalização do vínculo de trabalho no curso da ação fiscal. Muitos tiveram a Carteira de Trabalho como primeiro documento de identificação, e, desde 2004, houve a emissão de aproximadamente 36 
mil guias de Seguro-Desemprego especial para o Trabalhador Resgatado ${ }^{4}$, regido pela Lei $\mathrm{n}^{\circ}$ $10.608 / 2002$.

\section{CONSIDERAÇÕES FINAIS}

A questão do trabalho escravo na cadeia produtiva regional do açaí nunca foi analisada com amplitude, tampouco os riscos e os desafios existentes foram efetivamente dimensionados e enfrentados.

É total a invisibilidade da segurança do trabalho perante o consumidor final o que faz que os elos fortes da cadeia de valor (indústrias, atacadistas, varejistas e batedores) não se responsabilizem pela segurança do trabalhador (FUNDACENTRO, 2016).

Essa invisibilidade é um dos desafios enfrentados no combate ao trabalho escravo nas cadeias de valor regional, isso porque, nós, consumidores, desconhecemos a precariedade do trabalho exercido por esses trabalhadores, e, por conta disso, deixamos de pressionar os elos mais fortes da cadeia, na busca por melhores condições de trabalho e pela efetividade da proteção dos direitos fundamentais trabalhistas desses trabalhadores.

Ainda subsistem inúmeros pontos a serem aprimoradas a fim de construir um sistema efetivo de combate ao trabalho escravo, de punição dos responsáveis e de reparação às vítimas.

No entanto, houve investimento na criação de um sistema punitivo mais incisivo, a exemplo disso, a alteração legislativa do artigo 149 do código penal (Lei nº10. 803/2003), com o acréscimo do artigo 149-A (Lei n 13.344/2016) que contempla vários núcleos verbais e constituiu um importante avanço no combate (prevenção e repressão) ao trabalho análogo ao escravo.

Apesar dos avanços no combate ao trabalho escravo no Brasil, como a criação, em 1995, do Grupo Especial de Fiscalização Móvel (GEFM), que viabilizou o resgate de dezoito trabalhadores, dentre eles dois menores de idade, em situação de trabalho análogo ao de escravo na atividade de extrativismo de açaí em várzea, na Ilha do Marajó, no Pará, muitos ainda são os desafios a serem superados

\footnotetext{
${ }^{4}$ É um auxílio temporário concedido ao trabalhador comprovadamente resgatado de regime de trabalho forçado ou da condição análoga à de escravo. Tendo direito a no máximo três parcelas no valor de um salário mínimo.
} 
No entanto, com a extinção do Ministério do Trabalho e Emprego, e o sucateamento da Justiça do Trabalho, o grupo sofreu com a falta de incentivo público e hoje conta com apenas metade do número de grupos atuantes.

A informalidade nas relações de trabalho e a alta insegurança para a saúde no manejo de recursos naturais, conforme foi reiteradamente destacado ao longo do texto, são desafios ainda pouco debatidos dentro do cenário acadêmico.

Aliada à discussão acadêmica, a participação dos demais atores da cadeia é fundamental para que haja isso ocorra principalmente os que possuem elos mais fortes, maior poder aquisitivo e maior influência para combater essa precariedade.

A divulgação e o debate acerca dos problemas enfrentados, na cadeia de valor do açaí, pelo "Peconheiro" deve fomentar a reflexão, o debate e a cobrança dos demais componentes da cadeia produtiva, atravessadores, supermercados, batedores de açaí e do Poder Público quanto à implementação de medidas que assegurem a extração do produto de forma segura (FERREIRA; KOURY, 2018)

Segundo o relatório do Instituto Peabiru, dentre as soluções imediatas, acredita-se que medidas simples, como o desenvolvimento e aplicação de novas tecnologias para a extração e manejo do açaí podem diminuir significativamente os riscos (FUNDACENTRO, 2016).

Alertam os pesquisadores para a necessidade da retirada da atividade da informalidade, regulamentando as condições mínimas de segurança e trabalho, ouvindo os agentes envolvidos diretamente na atividade, os peconheiros e suas famílias, e, principalmente, discutir essas questões com a comunidade, num processo de educação e alerta.

Por fim, a pesquisa verificou que a ocupação do coletor de açaí não é reconhecida, o que precisa ser corrigido. Agrava-se a questão da informalidade dos contratos de terceirização, todos verbais e não documentados, principalmente, o que permite afirmar que o peconheiro que trabalha para um terceirizado, na verdade, está submetido a um sistema ainda mais frágil, de quarteirização informal. 


\section{REFERÊNCIAS}

BITENCOURT, Cezar Roberto. Tratado de Direito Penal, 2: parte especial: dos crimes contra a pessoa. 9. ed. São Paulo: Saraiva, 2009. p. 398.

BRITO FILHO, José Claudio Monteiro de. Trabalho decente: análise jurídica da exploração do trabalho - trabalho escravo e outras formas de trabalho indigno. 5. ed. atual. de acordo com a reforma trabalhista. São Paulo: LTr, 2018.

BRITO FILHO. José Claudio Monteiro de. Trabalho Escravo: Caracterização Jurídica. $2^{\mathrm{a}}$ Ed. São Paulo: Ltr Editora, 2017.

CANTO, Sérgio Aruana Elarrat. Processo Extrativista do açaí: Contribuição da Ergonomia com base na Análise Postural durante a Coleta dos Frutos. Dissertação aprovada para a obtenção do título de mestre em Engenharia de Produção no Programa de Pós-Graduação em Engenharia de Produção da Universidade Federal de Santa Catarina. Dez 
2001.

Disponível

em:

https://repositorio.ufsc.br/bitstream/handle/123456789/81677/185527.pdf?sequence=1\&isAll owed=y. Acesso em: 05 jul 2020.

FERREIRA, Otávio Bruno Silva; KOURY, Suzy Elizabeth Cavalcante. A segurança no trabalho do "peconheiro": necessidade de criação de uma política pública. In: Direitos sociais e políticas públicas III, CONPEDI, 2019. Acesso em 25 jul 2020.

GRECO, Rogério. Curso de Direito Penal: parte especial. v. 2. 5. ed. Niterói: Impetus, 2008. p. 545.

MENDES, Felipe Prata; PAZ, Melissa Mika Kimura. A invisibilidade do meio ambiente de trabalho do "peconheiro" na cadeia de valor do açaí. In: Direito do trabalho e meio ambiente do trabalho I, CONPEDI, 2019. Acesso em 28 jul 2020

FUNDACENTRO; INSTITUTO PEABIRU. Relatório final para o Programa Trabalho Seguro. Belém (PA), 2016. Disponível em: file:///I:/o-peconheirodiagnostico-acai-peabirufundacentro_20170222110513\%20(1).pdf. Acesso em: 05 jul 2020.

FUNDACENTRO. Fundação Jorge Duprat Figueiredo de Segurança e Medicina do Trabalho. Disponível em: http://www.fundacentro.gov.br/. Acesso em: 22 jul 2020.

IBGE. Sistema IBGE de Recuperação Automática (SIDRA). Produção da Extração Vegetal e da Silvicultura (PEVS) 2019. Disponível em: https://sidra.ibge.gov.br/home/ipp/brasil. Acesso 30 jul 2020.

KANT, Immanuel. Fundamentação da Metafísica dos Costumes e Outros Escritos. Trad. Leopoldo Holzbach. São Paulo: Martin Claret, 2004, p. 58.

KOURY, Suzy Elizabeth Cavalcante. O Trabalho Infantil na Colheita do Açaí na Ilha do Marajó - PA. In: James Magno Araujo Farias. (Org.). Trabalho Decente. 1ªed.São Paulo: LTr, 2017, v. p. 49-55.

LOUREIRO, Violeta Refkalefsky. A Amazônia no Século XXI: novas formas de desenvolvimento. São Paulo: Empório do Livro, 2009.

MIRABETE, Julio Fabbrini. Manual de Direito Penal Brasileiro. São Paulo: RT, 2005.

MPT. Observatório digital de saúde e segurança do trabalho. Disponível em: <https://observatoriosst.mpt.mp.br/\#>. Acesso em: 11/11/2018.

PAZ, Melissa Mika Kimura. Indicação geográfica e etnodesenvolvimento: um meio para a valorização do açaí das ilhas de Belém. Disponível em: https://www.cesupa.br/MestradoDireito/dissertacoes/2019/DISSERTACAO_MELISSA_MIK A_KIMURA_PAZ.pdf. Acesso em: 10 jul 2020. 
ORGANIZAÇÃO INTERNACIONAL DO TRABALHO. Convenção $\mathbf{n}^{\mathbf{0}} \mathbf{1 0 5}$. Disponível em: https://www.ilo.org/brasilia/convencoes/WCMS_235195/lang—pt/index.htm. Acesso em: 19 nov 2019.

REPÓRTER BRASIL. Trabalho Escravo e Extrativismo Vegetal. Natália Suzuki (org.); equipe 'escravo, nem pensar'. - são Paulo, 2020. 7 p.: 20 x 21 il. Disponível em: file:///C:/Users/La\%C3\%ADs\%20Castro/Desktop/enp-extrativismo-vegetal-digital-1803.pdf. Acesso em: 20 jul 2020.

SEN, Amartya. Desenvolvimento como liberdade. São Paulo: Companhia das Letras, 2010.

SMARTLAB. Observatório da Erradicação do Trabalho Escravo e do Tráfico de Pessoas. Disponível em: https://smartlabbr.org/trabalhoescravo. Acesso em: 26 jul 2020.

SILVA, Harley. Socialização da natureza e alternativas de desenvolvimento na Amazônia Brasileira. Tese (doutorado): Programa de Doutorado em Economia do Centro de Desenvolvimento e Planejamento Regional da Universidade Federal de Minas Gerais, 2017. Disponível http://www.bibliotecadigital.ufmg.br/dspace/bitstream/handle/1843/FACEAP8RH2/harley_sil va_tese_doutorado.pdf?sequence=1. Acesso em: 25 jul 2020.

SAGAZ, Priscilla Telma Bernardes, As condições degradantes de trabalho Como modalidade de trabalho escravo. Brasil. Ministério Público Federal, 2017. 248 p. (Coletânea de 45 artigos; v. 1) Disponível em: http://www.mpf.mp.br/atuacaotematica/ccr2/publicacoes. Acesso em 29 jul 2020. 